\title{
Introduction to the Minitrack on Open Platform Ecosystems in Logistics: Business Models and Technologies
}

\author{
Peter Detzner \\ Fraunhofer IML \\ peter.detzner@iml.fraunhofer.de
}

Sören Kerner

Fraunhofer IML

soeren.kerner@iml.fraunhofer.de

\author{
Frederik Möller \\ TU Dortmund University \\ Fraunhofer ISST \\ frederik.moeller@tu-dortmund.de
}

Boris Otto

TU Dortmund University

Fraunhofer ISST

boris.otto@tu-dortmund.de

\section{Introduction}

The logistics industry is a crucial sector relevant to constructing and sustaining local, regional, and global supply chains. Every good must be transported, be it a finished product to a customer or a part that still needs to be processed. Supply chains require different stakeholders to work conjointly, ranging from suppliers to Original Equipment Manufacturers (OEM). Recently, the logistics domain has emerged as a prime example of the stark potential of optimization through data. Data are an enabler to shorten routes, optimize processes or offer logistics services, such as monitoring temperatures of pharmaceutical goods or digital maps for indoor localization of automated vehicles. To that end, logistics is an industry highly impacted by digitization and the optimization of its processes [1].

Logistics is particularly suited to be analyzed through an ecosystem lens as it is the organization of various stakeholders to execute inter-and intralogistical processes [2]. Given the landscape of heterogeneous logistics service providers, one approach is to facilitate the neutral organization of logistics ecosystems that employ an open-source approach to foster trust and extendibility of software services. An example of realizing that paradigm is the Silicon Economic Logistics Ecosystem ${ }^{I}$ project funded by the German Federal Ministry of Transport and Digital Infrastructure. The project uses open-source components and services to equip companies in logistics with up-to-date software components to develop new services or use them out-of-the-box.
The track 'Open Platform Ecosystems in Logistics: Business Models and Technologies' invited contributions in the field sketched above. For example, it focused on:

- New and emerging technologies in Logistics (e.g., robotics and automation)

- New business models in Logistics, their classification, and design

- Open ecosystems in logistics (e.g., platforms and third-party development through APIs).

\section{Open Platform Ecosystems in Logistics: Business Models and Technologies}

In this mini-track, we explicitly focused on ecosystem-views in Logistics. For example, that includes the dedicated analysis of platforms in logistics [3] and the corresponding generation of new digital services (e.g., [4]). Additionally, we looked for contributions exploring novel ways of incorporating data into logistical services (e.g., [5]).

The track received three submissions. One contribution was desk rejected, and the other two submissions were accepted, resulting in an acceptance rate of $66.66 \%$. Both accepted contributions were handled by the track-chairs of the track 'Internet and the Digital Economy.' Both contributions offer distinct views on platforms in logistics:

- The first accepted paper, 'Dimensions of B2B Platforms in Logistics - White Spot Analysis' by

\footnotetext{
${ }^{1}$ https://www.silicon-economy.com/
} 
Carina Culotta and Estelle Duparc [6], uncovers the white spots of digital B2B platforms in logistics. They do that by developing a database of 188 empirical objects, i.e., logistics firms, and analyzing them based on their services. The authors formulate white spots by contrasting the services with existing logistical functions, such as transport or storage.

- $\quad$ The second accepted paper, 'Evaluating Platform Openness in Logistics based on a Taxonomic Analysis' by Estelle Duparc, Carina Culotta, and Boris Otto [7], extends existing classifications in Logistics with a distinct platform-centric view. Additionally, the paper investigates empirical objects through the lens of 'platform openness', searching explicitly for aspects regarding open platform ecosystems.

\section{Conclusion}

Both accepted papers contribute to our understanding of digital logistics. They provide an indepth analysis of an evolving industry with different foci and report on exciting findings regarding the current coverage of $\mathrm{B} 2 \mathrm{~B}$ platforms in logistical functions and their openness. These submissions were the first ones since this mini track was offered for the first time. Nowadays, the field of logistics is facing a massive transformation. We are already looking forward to re-organizing this track for next year's edition of HICSS with minor adjustments.

\section{References}

[1] van Marwyk, K. and S. Treppte, 2016 logistics study on digital business models, 2016.

[2] Lamberjohann, M. and B. Otto, "A Systematic Literature Review of Ecosystems: An Approach to Introduce Logistics Ecosystems into Academia", in Proceedings of the 8th International Conference on Information Systems, Logistics and Supply Chain, Texas: USA. 2020.

[3] Möller, F., H. Bauhaus, C. Hoffmann, C. Niess, and B. Otto, "Archetypes of Digital Business Models in Logistics Start-Ups", in Proceedings of the 27th European Conference on Information Systems, Uppsala and Stockholm: Sweden. 2019.

[4] Heinbach, C., S. Hagen, and O. Thomas, "FreightLogistics-as-a-Service - Innovative Geschäftsmodelle für ein datengetriebenes Transportmanagement", HMD Praxis der Wirtschaftsinformatik, 58(3), 2021, pp. 580 594.

[5] Möller, F., M. Stachon, C. Hoffmann, H. Bauhaus, and B. Otto, "Data-Driven Business Models in Logistics: A Taxonomy of Optimization and Visibility Services", in
Proceedings of the 53rd Hawaii International Conference on System Sciences, Hawaii: USA. 2020.

[6] Culotta, C. and E. Duparc, "Dimensions of Digital B2B Platforms in Logistics - A White Spot Analysis", in Proceedings of the 55th Hawaii International Conference on System Sciences, Hawaii: USA. 2022.

[7] Duparc, E., C. Culotta, and B. Otto, "Evaluating Platform Openness in Logistics based on a Taxonomic Analysis", in Proceedings of the 55th Hawaii International Conference on System Sciences, Hawaii: USA. 2022. 